\title{
Perception of lung function, adherence to inhaled corticosteroids, and the role of peak expiratory flow feedback in paediatric asthma
}

\author{
James Y Paton
}

\begin{abstract}
The current BTS/SIGN asthma guideline emphasises that the diagnosis of asthma is a clinical one with no standardised definition of the type, severity or frequency of symptoms, nor of the findings on investigation that invariably leads to a diagnosis of asthma. ${ }^{1}$ However, central to all definitions of asthma is the presence of variable airflow obstruction. Documenting a history of changes in airflow obstruction either after bronchodilator treatment (reversibility) or spontaneously (variability) is an essential part of an asthma diagnosis, as well as contributing to assessment of asthma control.
\end{abstract}

The variability of asthma in an individual has led to management strategies that educate and empower patients, or parents, to adjust their own therapy within a framework agreed with their clinician. This approach of 'guided selfmanagement' has been shown to be effective in adults and children. ${ }^{2} 3$

Clark and Gong note that using a selfmanagement approach acknowledges that clinicians cannot provide direction for every disease contingency. For effective disease control, patients need to exercise a high degree of independent decision making about adjusting their treatment. To do so, patients need to develop their own skills in self-management. Selfmanagement is underpinned by the behavioural theory of self-regulation that has at its heart a cycle of 'observation-judgment -reaction/s' ${ }^{4}$ It is by repeated iterations of this cycle that patients develop their personal repertoire of asthma management strategies.

Two important questions necessarily arise. First, what observations best allow

Correspondence to Dr James Y Paton, School of Medicine, University of Glasgow, Royal Hospital for Sick Children, Yorkhill, Glasgow G3 8SJ, UK;

james.paton@glasgow.ac.uk the patient/parent to monitor their asthma? Studies of self-management training programmes have commonly based asthma plans on assessment of symptoms and/or peak flow monitoring. 2356

Then, second, how best do clinicians ensure that patients are appropriately guided towards effective disease control? One problem is that, over time, a large number of patients fail to take prescribed medications in ways that would currently be judged clinically appropriate. The question might then be recast as 'how does the clinician best enable the patient to use the asthma medication effectively in the long-term?"7 The simple answer is that often patients/parents are not persuaded and, either through choice or circumstances, do not take their medications as prescribed.

One important reason why patients with asthma may not take medication is that their perception of dyspnoea (POD) may be reduced. One study found that approximately $25 \%$ of adults with asthma attending a clinic had a low POD. When followed prospectively, those patients had significantly more emergency department visits, hospitalisations, near-fatal asthma attacks and deaths compared with those who had normal or high POD. ${ }^{8}$ A number of other studies have suggested that POD may be impaired in some adults with asthma, and that such impairment may be related to risk of death. ${ }^{9}$ In children, asthma symptom perception (assessed by comparing a child's subjective guess of their peak expiratory flow (PEF) with objective measures of lung function (PEF and forced expiratory volume $\left(\mathrm{FEV}_{1}\right)$ ) was associated with functional morbidity $^{10}$ at baseline, and prospectively over a 1-year follow-up. ${ }^{11}$ It appears that POD is not a stable trait, and that over- or underperception of asthma varies within an individual, and is influenced by contextual information. ${ }^{12}$
Are there ways that can improve POD and make patient's judgments and reactions more effective such that there is improved compliance and better asthma control? One potential way is through better feedback of relevant information. ${ }^{13}$ Immediate feedback of PEF might capture an individual's attention and improve symptom perception. An important development has been the availability of portable electronic spirometers that can easily provide feedback.

It is within this context that the article by Feldman et al should be viewed. ${ }^{14}$ Feldman et al have previously used programmable, portable spirometers that allow children to record both subjective estimates and objective measurements of PEF in the community. Using an Asthma Risk Grid, ${ }^{11}$ the authors then retrospectively assessed whether the child's estimates were accurate. Thus, a child estimating their peak flow as $85 \%$ personal best, where the measured peak flow was $55 \%$ of best, would be classified as a dangerous underperceiver of asthma severity. The authors have used this approach to investigate whether children who received feedback of their measured PEF would have less underperception of respiratory compromise, better adherence and less reliever use than children not receiving PEF feedback. ${ }^{14}$

Feldman et al recruited two convenience samples of children with asthma and their primary carers from asthma and primary care clinics, the emergency department and mailings: 104 children between 7 and 15 years of age who received PEF feedback; and a second group of 88 between 7 and 12 years of age who did not receive feedback. All the children were living in the Bronx in New York, and were of Puerto Rican, African-American or AfroCaribbean backgrounds, with over half the children living below the poverty threshold. The study ran over 6 weeks. Families were financially compensated for taking part. Each child was trained to use an electronic spirometer individualised with a sticker showing the child's own predicted PEF values presented as three traffic light zones ranging from a happy face to a sad face. Before performing a forced vital capacity (VC) manoeuver, the children were asked to enter an estimate of what they expected their peak flow would be. Each child then performed three VC manoeuvers with the best flow recorded. The number of inhaler actuations over the 6 weeks was counted for both preventative and quick-relief inhalers using Doser devices that record the number of actuations per day.

The authors found that children in the feedback group displayed greater accuracy, 
less under perception and greater over perception of respiratory compromise, and also better adherence to inhaled corticosteroids (ICS) and more quick-relief medication use than those in the no-feedback group. It is striking that better adherence to ICS meant a rise from a very poor average percent adherence of $27.5 \%$ in the 'no PEF feedback' group to $48.8 \%$ in the feedback group. During the time, the authors found no evidence of a learning effect in the PEF group.

Feldman et al acknowledge two important limitations. First, the study was non-randomised and made use of convenience sampling. As might be expected with non-randomised groups, there were age differences between the two groups ( $7-15$ years for the feedback group vs 7-12 years for the non-feedback group). There were also small differences in asthma control (better in the PEF group) although there were no differences in ICS prescription (used in approximately $60 \%$ of children), asthma severity (approximately 30\% severe), and asthma control (approximately 35\% very poorly controlled). The age difference is potentially important because, according to the authors, older children are more accurate in symptom perception, but less adherent to controller medications. ${ }^{14}$ However, after repeating the analysis excluding the older children, the authors found that the effects of feedback remained significant.

Two other limitations should be noted. First, this study lasted only 6 weeks, and valid data points for symptom perception were obtained in $48.7 \%$ of both groups. The authors do not provide data on percentage compliance with PEF measurement. In a previous study using similar methodology, Feldman et al reported the children used the electronic spirometer on average 31 out of 46 (67\%) days. Further, 28 of $226(12 \%)$ were excluded because they failed to collect a minimum of 20 data points. ${ }^{11}$ Thus, compliance with electronic spirometer use to measure POD even over a limited period of 6 weeks may be problematic. This confirms findings from other studies of electronic spirometers in adolescents ${ }^{15}$ and children ${ }^{16}$ where short-term monitoring was associated with high initial compliance with monitoring and good data quality both of which declined over time. Wensley and Silverman concluded that the optimal time for collecting spirometry data in children at home was 1 month. ${ }^{16}$ So it does not seem likely that long-term monitoring strategies using electronic spirometry for children are feasible.

Secondly, Feldman et al report training of the children in the use of the spirometers, but say nothing about asthma management education or other aspects of self-management. In other studies, selfmanagement decisions have usually been based on symptoms. ${ }^{2} 3$ The role of PEF monitoring either as an adjunct or in the form of PEF-based plans is unclear. ${ }^{5}{ }^{6}$ In one randomised trial of PEF plus symptombased management or symptom-based management alone in 7-14-year-old children with moderate asthma, there were no differences in mean symptom score, PEF, spirometric lung function, quality of life or reported health service use over 12 weeks. Further, during acute episodes, children responded to changes in symptoms by increasing their inhaled steroids at a mean PEF value of greater than $70 \%$ of best, so that overall PEF did not contribute even during exacerbations. This echoes other studies that suggest that symptoms may be more useful in assessing asthma control in the longer term than $\mathrm{PEF}^{17}$

Thus, Feldman et al's demonstration that feedback of PEF can influence POD in a short-term study is interesting. However, it does not address the key question. Can a usable system of monitoring be developed such that children can sustain compliance over a long period of time, and that can lead to measurable improvements in desirable asthma outcomes? ${ }^{13} 18{ }^{19}$ We now have signals (symptoms, PEF, symptom perception, individual conditional probabilities $^{20}$ ) that can highlight changes in control, appropriate and effective therapies, desirable outcomes, ${ }^{21}$ relevant theoretical behavioural frameworks, ${ }^{22}$ and new electronic technologies (spirometers, diaries, the internet and portable communication tools, especially mobile phones). The challenge is how to combine these tools so that children and their parents can achieve improved asthma outcomes.

\section{Competing interests None.}

Provenance and peer review Commissioned internally peer reviewed

Published Online First 5 September 2012

Thorax 2012;67:1023-1024.

doi:10.1136/thoraxjnl-2012-202244

\section{REFERENCES}

1. British Guideline on the management of asthma. Thorax 2008;63(Suppl 4):iv1-121.

2. Wolf FM, Guevara JP, Grum CM, et al. Educational interventions for asthma in children. Cochrane Database Syst Rev 2003:CD000326.
3. Gibson PG, Powell H, Coughlan J, et al. Self-management education and regular practitioner review for adults with asthma. Cochrane Database Syst Rev 2003:CD001117.

4. Clark NM, Gong M. Management of chronic disease by practitioners and patients: are we teaching the wrong things? BMJ 2000;320:572-5.

5. Powell H, Gibson PG. Options for self-management education for adults with asthma. Cochrane Database Syst Rev 2003:CD004107.

6. Zemek RL, Bhogal SK, Ducharme FM. Systematic review of randomized controlled trials examining written action plans in children: what is the plan? Arch Pediatr Adolesc Med 2008;162. 157-63.

7. Haynes RB, Ackloo E, Sahota N, et al. Interventions for enhancing medication adherence. Cochrane Database Syst Rev 2008:CD000011.

8. Magadle R, Berar-Yanay N, Weiner P. The risk of hospitalization and near-fatal and fatal asthma in relation to the perception of dyspnea. Chest 2002;121:329-33.

9. Aldrich TK. Pink puffers vs blue bloaters in asthma too? Chest 2002;121:313-15.

10. Rosier MJ, Bishop J, Nolan T, et al. Measurement of functional severity of asthma in children. Am J Respir Crit Care Med 1994;149:1434-41.

11. Feldman JM, McQuaid EL, Klein RB, et al. Symptom perception and functional morbidity across a 1-year follow-up in pediatric asthma. Pediatr Pulmonol 2007:42:339-47.

12. Janssens T, Verleden G, De, et al. Inaccurate perception of asthma symptoms: a cognitive-affective framework and implications for asthma treatment. Clin Psychol Rev 2009;29:317-27.

13. Burgess SW, Sly PD, Devadason SG. Providing feedback on adherence increases use of preventive medication by asthmatic children. J Asthma 2010;47:198-201.

14. Feldman J, Kutner $\mathrm{H}$, Matte L, et al. Perception of lung function, adherence to inhaled corticosteroids, and the role of peak expiratory flow feedback in paediatric asthma. Thorax 2012. doi:10.1136/ thoraxinl-2012-201789.

15. van der Meer V, Rikkers-Mutsaerts ER, Sterk PJ, et al. Compliance and reliability of electronic PEF monitoring in adolescents with asthma. Thorax 2006:61:457-8.

16. Wensley DC, Silverman M. The quality of home spirometry in school children with asthma. Thorax 2001;56:183-5.

17. Sharek PJ, Mayer ML, Loewy L, et al. Agreement among measures of asthma status: a prospective study of low-income children with moderate to severe asthma. Pediatrics 2002;110:797-804.

18. Burgess S, Sly P, Devadason S. Adherence with preventive medication in childhood asthma. Pulm Med 2011;2011:973849.

19. Burgess SW, Sly PD, Morawska A, et al. Assessing adherence and factors associated with adherence in young children with asthma. Respirology 2008;13:559-63.

20. Thamrin C, Zindel J, Nydegger R, et al. Predicting future risk of asthma exacerbations using individual conditional probabilities. J Allergy Clin Immunol 2011;127(6):1494-502 e3.

21. Clark NM, Griffiths C, Keteyian SR, et al. Educational and behavioral interventions for asthma: who achieves which outcomes? A systematic review. J Asthma Allergy 2010;3:187-97.

22. Clark NM, Valerio MA. The role of behavioural theories in educational interventions for paediatric asthma. Paediatr Respir Rev 2003;4:325-33. 